\title{
Therapeutic value of colchicine in the treatment of patients with psoriatic arthritis
}

\author{
Robert J R McKendry, Gunnar Kraag, Stuart Seigel, Adel Al-Awadhi
}

\begin{abstract}
Objective-To test the hypothesis that colchicine is an effective treatment of psoriatic arthritis.

Methods-Twenty five patients with psoriatic arthritis were entered into a two centre, double blind, crossover study of 23 weeks' duration comparing the therapeutic effect of colchicine (0.6-1.8 mg/day) with placebo.

Results-No significant difference was noted between colchicine or placebo treatment for the primary outcome measure (Lansbury joint count) or any of the seven secondary outcome measures. No change in the psoriasis was noted during active or placebo treatment. Adverse clinical effects were reported more often during treatment with colchicine (14 patients) than with the placebo (four patients), resulting in the early withdrawal of three patients receiving colchicine from the trial. Increased creatine kinase values, without weakness, occurred during treatment with colchicine (five patients) and placebo (four patients).

Conclusions-In conclusion, our study did not provide evidence that colchicine is of therapeutic value in the treatment of psoriatic arthritis.
\end{abstract}

(Ann Rheum Dis 1993; 52: 826-828)

Current treatments for psoriatic arthritis are only partially effective and are often associated with significant adverse effects. ${ }^{1}$ Colchicine has been suggested as a beneficial, inexpensive, and safe alternative in the management of psoriasis and psoriatic arthritis. ${ }^{2} 3$

Department of Medicine, Rheumatic Disease Units, Ottawa General Hospital and Ottawa Civic Hospital, University of Ottawa, Ottawa, Canada R J R McKendry

G Kraag

$S$ Seigel

A Al-Awadhi

Correspondence to: Dr Robert J R McKendry, Ottawa General Hospital, Rheumatic Disease Unit, 50 Smyth Road, Room LM-10 Ottawa, Ontario, Canada K1H 8L6.

Accepted for publication 13 July 1993
Patients and methods

Patients with arthritis and psoriasis were referred for this study by rheumatologists affiliated with the University of Ottawa rheumatic disease units. Twenty five of the 31 patients referred met the inclusion/exclusion criteria and provided informed consent. The inclusion criteria were: age $\geqslant 18$ years, psoriasis diagnosed by a dermatologist, and active synovitis (tenderness or effusion, or both) in three or more joints. The exclusion criteria were: women with inadequate contraception, history of inflammatory bowel disease, liver disease, renal disease, bone marrow hypoplasia, increased creatine kinase, or a rheumatoid factor (latex) test greater than $1 / 80$. All patients continued existing treatment, including non-steroidal anti-inflammatory drugs (NSAIDs), low doses of prednisone, or low doses of methotrexate at a constant dose for at least three weeks before and during the study period.

STUDY DESIGN

The double blind, randomised, placebo controlled, crossover design of 23 weeks' duration included a one week pretrial washout followed by eight weeks of treatment with placebo or colchicine, then a one week midtrial washout period before switching to the alternative treatment for the second eight week period. This 18 week crossover part of the study was followed by two follow up visits while not receiving the study drugs (post-trial washout) at weeks 19 and 23 . The patients were randomised by computer code for their study drugs. Each group began with one tablet a day (either $0.6 \mathrm{mg}$ colchicine or identical placebo) for the first seven days, one tablet twice a day for the second seven days, and then one tablet three times a day for the remaining six weeks. If suspected drug reactions occurred the patient was instructed to decrease the dose to the previous level until the adverse effects were tolerable, and then to try the higher dose again. Those who were unable to tolerate the higher dose rechallenge continued to receive the lower dose. Any patient who was unable to tolerate the drug at $0.6 \mathrm{mg}$ once daily was dropped from the study.

All patients kept daily diaries of concurrent drugs, the study drug regimen, and any perceived adverse effects.

METHODS OF EVALUATION

Clinical evaluations were performed at week 0 (pretrial washout), week 1 (start of initial course of colchicine/placebo), weeks 5, 9, 10 (end of midtrial washout, and the beginning of the second course of colchicine/placebo), weeks 14, 18 (end of second course of colchicine/placebo), week 19 (one week posttrial washout), and week 23 (five week posttrial washout). Most of these evaluations were performed by two blinded investigators (SS or AAA) at two centres.

Clinical assessment of the psoriatic rash included the evaluation of five body surface areas as described by Seidman ${ }^{2}$ : a clearcut pathological finding was recorded as two points, a questionable or uncertain observation 
as one point, and skin with a normal appearance as 0 (modified to include the scalp). The assessment of psoriatic arthritis was made using the Lansbury joint count, ${ }^{4}$ number of swollen joints, morning stiffness (minutes), grip strength (using standardised cuff at $20 \mathrm{mmHg}$ ), proximal interphalangeal/ distal interphalangeal joint circumference (using an arthrocircumeter), the arthritis impact measurement scales (AIMS) for activities of daily living, ${ }^{5}$ pain measured on a 0-100 visual analogue scale, and the global assessment (on a four point scale as $1=$ poor, 2 =fair, $3=$ good, and 4 =excellent) by the patient and doctor.

Laboratory evaluations included haemoglobin (mean 140-180 g/l; women 120-160 $\mathrm{g} / \mathrm{l})$, white blood cell count $\left(4 \cdot 0-10 \cdot 0 \times 10^{9} / 1\right)$, platelet count $\left(150-400 \times 10^{9} / 1\right)$, erythrocyte sedimentation rate (men $0-10 \mathrm{~mm} / \mathrm{h}$; women 0-20 $\mathrm{mm} / \mathrm{h}$ Wintrobe), urea $(3.5-9.0 \mathrm{mmol} / \mathrm{l})$, creatinine $(70-130 \mu \mathrm{mol} / \mathrm{l})$, aspartate transaminase (7-40 U/l), alkaline phosphatase (30-110 U/I), and creatine kinase (men 15-170 U//; women 30-130 U/1). A rheumatoid factor latex fixation test and radiographs of the hands, feet, and sacroiliac joints were obtained at baseline only.

At each visit patients were questioned for possible adverse effects or drug changes. At the end of the study each patient was asked to compare the two treatment periods.

Table 1 Lansbury joint count: primary outcome measure

\begin{tabular}{|c|c|c|c|c|}
\hline \multirow[t]{2}{*}{ Patient No } & \multicolumn{2}{|c|}{ Intragroup (gain score)* } & \multicolumn{2}{|l|}{ Intergroupt } \\
\hline & Colchicine & Placebo & Colchicine & Placebo \\
\hline $\begin{array}{r}1 \\
2 \\
3 \\
4 \\
5 \\
7 \\
13 \\
14 \\
16 \\
19 \\
20 \\
21 \\
22 \\
24 \\
25\end{array}$ & $\begin{array}{r}-47 \\
-28 \\
1 \\
2 \\
10 \\
21 \\
0 \\
5 \\
4 \\
-1 \\
3 \\
-6 \\
-1 \\
-5 \\
-7\end{array}$ & $\begin{array}{r}13 \\
-9 \\
-10 \\
-3 \\
-11 \\
-32 \\
-5 \\
-13 \\
-33 \\
-7 \\
3 \\
2 \\
-16 \\
-4 \\
-5\end{array}$ & $\begin{array}{r}14 \\
9 \\
2 \\
15 \\
12 \\
45 \\
8 \\
29 \\
76 \\
6 \\
10 \\
5 \\
40 \\
4 \\
34\end{array}$ & $\begin{array}{r}36 \\
29 \\
18 \\
20 \\
7 \\
16 \\
7 \\
12 \\
52 \\
3 \\
12 \\
11 \\
34 \\
8 \\
61\end{array}$ \\
\hline Total & $-3 \cdot 3 \ddagger$ & $-8 \cdot 7 \ddagger$ & $20 \cdot 6 \pm 20 \cdot 5 \ddagger$ & $21 \cdot 7 \pm 17 \cdot 3 \ddagger$ \\
\hline
\end{tabular}

*Week 9 or 18 minus baseline values (a negative value indicates a degree of improvement). †Actual Lansbury joint count at week 9 or 18 .

$\neq p=0.42$ (NS) for intragroup; $p=0.79$ (NS) for intergroup.

\section{STATISTICAL ANALYSIS}

Intragroup analysis-that is, gain score (covariance analysis) of pretrial and end of trial outcome measures, as well as intergroup analysis - that is, comparisons between the placebo and treatment groups-were performed using a Compaq 386SX personal computer and the University of Ottawa mainframe CMS with the biomedical data processing (BMDP) and SPSSX statistical software packages.

The Lansbury joint count was preselected as the principal outcome measure, and a $50 \%$ improvement from baseline, or a $30 \%$ difference between active and placebo treatment, was considered a clinically significant response. Non-parametric statistics were used to complement the analysis of variance where appropriate. The $\chi^{2}$ and Fisher's exact test are used for nominal data $(\alpha 0.05)$.

\section{Results}

Twenty five subjects (14 men) met the enrolment criteria. At entry these 25 patients wi:- psoriasis and arthritis had a mean (SD) age of $40.7(11.8)$ years, 23 of 25 were receiving concurrent NSAID treatment, and seven were also being treated concurrently with methotrexate. Clinical baseline measurements showed that most patients had moderately active synovitis: mean Lansbury count $24 \cdot 2$, more than one hour of morning stiffness, $6 \cdot 0$ swollen joints, but mild psoriasis with an average skin score of only $4 \cdot 8$. There was radiological evidence of sacroiliac joint disease in three patients.

Comparisons of the final outcome assessments were performed on the 15 patients who completed the entire 23 week study. There was no significant difference in the primary outcome measure (the Lansbury joint count) at the end of eight weeks of colchicine treatment compared with placebo (table 1). No significant intragroup change (gain score) in the Lansbury joint count during treatment with colchicine or placebo was noted. Twelve patients recorded a more than $30 \%$ improvement, four receiving colchicine and eight on placebo treatment (data not shown). With a single exception there was no significant difference in any of the other seven outcome measures between colchicine and placebo treatment (table 2 ). The statistically significant

Table 2 Comparison of outcome measures at completion of washout periods and completion of colchicine or placebo treatment. Values are mean (SD) of the 15 patients who completed the trial

\begin{tabular}{|c|c|c|c|c|c|c|c|}
\hline & $\begin{array}{l}\text { End of washout } \\
\text { period } \\
\text { (week } 1 \text { or 10) }\end{array}$ & $\begin{array}{l}\text { Colchicine } \\
\text { (week } 9 \text { or 18) }\end{array}$ & $\begin{array}{l}\text { p Value } \\
\text { (washout } \mathrm{v} \\
\text { colchicine) }\end{array}$ & $\begin{array}{l}\text { End of washout } \\
\text { period } \\
\text { (week } 1 \text { or 10) }\end{array}$ & $\begin{array}{l}\text { Placebo } \\
\text { (week } 9 \text { or 18) }\end{array}$ & $\begin{array}{l}\text { p Value } \\
\text { (washout } \mathrm{v} \\
\text { placebo) }\end{array}$ & $\begin{array}{l}\text { p Value } \\
\text { (colchicine v } \\
\text { placebo) }\end{array}$ \\
\hline Pain (VAS) & $50 \cdot 2(25 \cdot 9)$ & $49 \cdot 0(20 \cdot 9)$ & NS & $60 \cdot 1(22 \cdot 1)$ & $44 \cdot 6(23 \cdot 6)$ & $0 \cdot 02$ & NS \\
\hline $\begin{array}{l}\text { Morning stiffness } \\
\text { (minutes) }\end{array}$ & $43 \cdot 0(47 \cdot 8)$ & $44 \cdot 5(37 \cdot 0)$ & NS & $69 \cdot 7(64 \cdot 5)$ & $60.3(53.5)$ & NS & NS \\
\hline Grip strength (right) & $204 \cdot 8(103 \cdot 8)$ & $223.3(93.2)$ & NS & $203.3(97 \cdot 5)$ & $195.0(95 \cdot 8)$ & NS & NS \\
\hline Grip strength (left) & $221.0(91.4)$ & $224.7(91 \cdot 3)$ & NS & $210 \cdot 0(100 \cdot 4)$ & $196 \cdot 6(104 \cdot 3)$ & NS & NS \\
\hline No of swollen joints & $5.8(2.5)$ & $5 \cdot 5(3 \cdot 2)$ & NS & $5 \cdot 3(2 \cdot 1)$ & $5.1(3.9)$ & NS & NS \\
\hline $\begin{array}{l}\text { Circumference of PIP } \\
\text { joints (mm) }\end{array}$ & $430 \cdot 6(62 \cdot 4)$ & $429.9(63.9)$ & NS & $420 \cdot 2(50 \cdot 6)$ & $415 \cdot 8(52 \cdot 6)$ & NS & NS \\
\hline $\begin{array}{l}\text { Circumference of DIP } \\
\text { joints (mm) }\end{array}$ & $364.9(47 \cdot 4)$ & $361 \cdot 6(43 \cdot 3)$ & NS & $354.5(31.4)$ & $361 \cdot 8(36 \cdot 0)$ & NS & NS \\
\hline
\end{tabular}

Abbreviations: $\mathrm{VAS}=$ Visual analogue scale; $\mathrm{PIP}=$ proximal interphalangeal; $\mathrm{DIP}=$ distal interphalangeal 
improvement in pain on placebo treatment $(p=0.022)$ is not corrected for the number of variables tested. There was no difference in the global assessment or AIMS score between the colchicine and placebo treatment (data not shown). No order effect was detected. Eight patients judged that the placebo and colchicine treatment were equally effective, four preferred colchicine and three preferred the placebo. No change in the skin score for psoriatic rash was noted in either group.

Laboratory measures were unchanged during colchicine treatment with the notable exception of creatine kinase values which increased in 12 of 15 colchicine treatment courses for which creatine kinase values before and after treatment were available (before $101.6(66 \cdot 2)$; after $131 \cdot 0(83 \cdot 5))$. The creatine kinase after eight weeks of colchicine treatment exceeded the upper limit of normal (women 130, men $170 \mathrm{U} / \mathrm{l}$ ) in five patients $(396,200$, 552,277 , and $210 \mathrm{U} / \mathrm{l}$ ). At the end of eight weeks of placebo treatment, however, four patients also had creatine kinase values higher than the upper limit of normal $(534,262,399$, and $228 \mathrm{U} / 1$ ). No patients reported weakness, and none had the increased serum creatine levels previously associated with an increased risk of colchicine neuromyopathy. ${ }^{6}$ Ten patients did not complete the full 23 week trial. Four dropped out owing to adverse effects (three with diarrhoea and abdominal pain while receiving colchicine), one for lack of efficacy, and five for not following the regimen.

Adverse effects were reported by four patients during treatment with placebo and 14 patients during treatment with colchicine. Two patients reported adverse clinical effects during one of the three washout periods. Gastrointestinal symptoms (usually abdominal cramps or diarrhoea, or both) led to a submaximal dose of colchicine in 17 patients. Of the 15 patients completing the study three completed on a twice daily dose and four on a single daily dose of colchicine.

\section{Discussion}

In 1987 Seidman et al published a randomised, double blind, 16 week crossover pilot study of 15 patients with psoriatic arthritis showing that colchicine $(1.5 \mathrm{mg} /$ day $)$ was more effective than placebo. ${ }^{2}$ This study reported a significant improvement in grip strength, Ritchie index, joint size, joint pain, and the overall therapeutic assessment, but no change in psoriatic skin lesions. These results supported an earlier open study reporting decreased arthralgia in patients with psoriasis treated with colchicine. $^{3}$

We attempted to reproduce Seidman's study using a larger number of patients, the same duration of colchine/placebo treatment, similar entry criteria (though we allowed any concomitant treatment at a constant dose), and similar outcome measures. Unlike Seidman, we used pre-, mid-, and poststudy single blind washout periods. Seidman's study allowed the use of a rescue analgesic (dextropropoxifen 50 $\mathrm{mg}$ ), though the amount used was not reported.

Unlike Seidman et al we did not find a significant difference between colchicine and placebo treatment using the primary outcome measure (Lansbury joint count) or six of the seven secondary outcome measures. Colchicine was significantly more toxic than placebo with three patients discontinuing colchicine owing to gastrointestinal side effects, usually diarrhoea, abdominal pain, or nausea, or a combination of these. Four of the 10 patients who did not complete the study dropped out in the initial five weeks, precluding their incorporation in a meaningful intent to treat analysis. Our finding of modestly increased creatine kinase levels in the colchicine and placebo treatment groups is unexplained.

The results of Seidman's pilot study might be explained by invoking a type I error. Alternatively, our study is also small and subject to a type II error. The results from 15 patients completing the study could detect a real difference between groups for a Lansbury joint count of 17 or greater (assuming $\alpha=0.05$ and power $=0 \cdot 8$ ). There was no trend towards a therapeutic effect for colchicine, either by comparing the means before and after treatment for each group, or by using the results of outcome measures for individual patients. For example, only three patients with $a \geqslant 30 \%$ improvement in the Lansbury joint count when receiving colchicine also had a $\leqslant 30 \%$ improvement while receiving placebo.

In conclusion, our study did not provide evidence that colchicine is therapeutic in psoriatic arthritis.

The authors are deeply grateful to Ms P Dale (research assistant-RDU) for compilation and statistical analysis of the data and preparation of the manuscript.

1 Gerber L H, Espinoza L R. Psoriatic arthritis. Florida: Grune and Stratton, 1985

2 Seidman P, Fjellner B, Johannesson A. Psoriatic arthritis treated with oral colchicine. $\mathcal{F}$ Rheumatol 1987; 14 $777-9$.

3 Whab A, Cohen A S. Therapeutic trials with oral colchicine in psoriasis. Acta Derm Venereol 1980; 60: 515-20.

4 Buchanan W W, Tugwell P. Clinical evaluation in rheumatic diseases. Arthritis and allied conditions. Philadelphia: Lea and Febiger, 1985.

5 Meenan R F. New approaches to outcome assessment: the AIMS questionnaire for arthritis. Boston, Massachusetts: Year Book Medical Publishers, 1985.

6 Kuncl R W, Duncan G, Watson D, Alderson K, Rogawsk M A, Peper M. Colchicine myopathy and neuropathy. $N$ Engl f Med 1987; 316: 1562-8. 